\title{
Instability of a pEA29 Marker in Erwinia amylovora Previously Used for Strain Classification
}

E. L. Schnabel and A. L. Jones, Department of Botany and Plant Pathology and the Pesticide Research Center, Michigan State University, East Lansing 48824-1312

\begin{abstract}
Schnabel, E. L., and Jones, A. L. 1998. Instability of a pEA29 marker in Erwina amylovora previously used for strain classification. Plant Dis. 82:1334-1336.

We examined the use of previously observed restriction fragment length polymorphisms (RFLPs) of a polymerase chain reaction (PCR)-amplified fragment of plasmid pEA29 for differentiating strains of Erwinia amylovora. The PCR fragment from E. amylovora strain CA11 contains a region of 8-bp tandem repeats which is predicted to cause the RFLPs. Examination of a collection of 93 strains revealed the repeat sequence GATTACA(GAATTACA) ${ }_{n}$ GAATTATCA in pEA29 with $n$ ranging from 3 to 14 . Selected strains were examined after growth in liquid culture to establish the stability of this character. Four strains originally with $n=14,13,7$, and 3 repeats were grown overnight in liquid culture and streaked onto agar plates to produce individual colonies. Respectively, 4, 10, 1, and 0 out of 17 colonies per strain had an altered copy number when retested. Considering the instability in the number of repeats, it is concluded that the polymorphism in this region of pEA29 is not useful as a marker for following the migration of E. amylovora.
\end{abstract}

The development of a system for characterizing and tracking Erwinia amylovora strains would be of great use in monitoring epidemics and tracing regional outbreaks of antibiotic-resistant strains. Replication extragenic palindromic-polymerase chain reaction (Rep-PCR), PCR ribotyping, nutrient-utilization assessment, fatty acid analysis, and random amplified polymorphic DNA fragment analysis have shown that strains of E. amylovora from apple and pear are genetically homogeneous $(3,6,9$, $10,13)$. An examination of $E$. amylovora strains by pulsed-field gel electrophoresis (PFGE) after digestion of genomic DNA with rare cutting restriction enzymes indicated that it may be possible to trace outbreaks of fire blight on Malus and Pyrus spp. (14). However, the restriction fragment length polymorphism observed by Lecomte et al. (5) in plasmid pEA29, if reliable, would be a significantly easier method than PFGE for elucidating the

Corresponding author: A. L. Jones E-mail: jonesa@pilot.msu.edu

Current address: Michigan State University, 103 Pesticide Research Center, East Landing, MI 48824.

This research was supported in part by the Michigan Apple Research Committee, the Michigan Agricultural Experiment Station, and USDA/ CSREES Agreement 97-34367-3967.

Accepted for publication 22 August 1998.

Publication no. D-1998-1002-01R

(C) 1998 The American Phytopathological Society origin and migration of E. amylovora strains.

There has been widespread application of molecular assays based on a PstI fragment (fragment F) of pEA29 to identify colonies of $E$. amylovora and to detect $E$. amylovora in extracts from symptomatic and asymptomatic plants $(1,8)$. Size variation in the PCR product generated by primers for this region of pEA29 was observed by Lecomte et al. (5). Strains from a worldwide collection of E. amylovora were divided into three groups based on the size of a 250- to 340-bp Sau3A fragment and a 370- to 450-bp MspI fragment derived from the pEA29 PCR product. They proposed that this length variation be used as a marker for tracing the movement of a group of E. amylovora currently found only in Austria and in southern Germany. Strains belonging to two additional groups were distributed worldwide.

The objective of our research was to determine the basis for the variability in the PCR product from plasmid pEA29 and to assess its potential usefulness for differentiating migrating populations of $E$. amylovora, including streptomycin-resistant strains.

\section{MATERIALS AND METHODS}

Bacterial strains and culture conditions. A total of 89 strains of E. amylovora from apple orchards in nine counties in Michigan were analyzed by PCR. Strain Ea110 was collected in 1975 (12), strains EL01 and CA11 in 1990 (2), and the remaining Michigan strains were collected from 1992 to $1994(7,9)$ and had previously been characterized for resistance to streptomycin. The group included 57 sensitive strains and 6 and 24 strains with resistance due to rpsL mutation or strA$s t r B$ streptomycin-modifying genes, respectively. Four additional strains from Illinois (raspberry, strain IL5), Oregon (pear, OR24), Washington (apple, WD2), and New Zealand (unknown host, NZR6) were also analyzed. Strains were cultured on Luria-Bertani agar (per liter: $10 \mathrm{~g}$ tryptone, $5 \mathrm{~g}$ yeast extract, $5 \mathrm{~g} \mathrm{NaCl}, 15 \mathrm{~g}$ Bacto-Agar) and incubated for $48 \mathrm{~h}$ at $22^{\circ} \mathrm{C}$. Liquid cultures were grown overnight at $28^{\circ} \mathrm{C}$ with shaking at $250 \mathrm{rpm}$.

Polymerase chain reaction. Bacteria were suspended in $50 \mu \mathrm{l}$ deionized $\mathrm{H}_{2} \mathrm{O}$. PCR mixtures $(20$ to $100 \mu \mathrm{l})$ consisted of $10 \mathrm{mM}$ Tris- $\mathrm{HCl}(\mathrm{pH} 8.3), 50 \mathrm{mM} \mathrm{KCl}$, $1.5 \mathrm{mM} \mathrm{MgCl} 2,0.1 \%$ Tween-20, $160 \mu \mathrm{M}$ each dNTP, 0.5 to $1.0 \mu \mathrm{M}$ each primer, 0.025 units $/ \mu 1$ Taq DNA Polymerase (Gibco/BRL, Grand Island, NY), and 2 to $5 \mu 1$ of bacterial suspension. Primer pairs were AJ75 (5'-CGTATTCACGGCTTCGCAGAT-3') and AJ76 (5'-ACCCGCCAGGATAGTCGCATA-3'), or 29RPT-F (5'-CTTACTTAGCCATAACGCAACAA$\left.3^{\prime}\right)$ and 29RPT-R (5'-CAGAAGCCGGATGTCTTTC-3'). Primers were synthesized by the Michigan State University (MSU) Macromolecular Structure Facility (East Lansing). Reactions were carried out in an MJ Research PTC-100 thermocycler equipped with a heated lid. Cycling parameters for $\mathrm{AJ} 75 / \mathrm{AJ} 76$ reactions were $95^{\circ} \mathrm{C}$ for $5 \mathrm{~min}$ followed by 40 cycles of $92^{\circ} \mathrm{C}$ for $1 \mathrm{~min}, 56^{\circ} \mathrm{C}$ for $1 \mathrm{~min}$, and $72^{\circ} \mathrm{C}$ for $2 \mathrm{~min}$. Cycling parameters for 29RPTF/29RPT-R reactions were $94^{\circ} \mathrm{C}$ for 5 minutes followed by 30 cycles of $94^{\circ} \mathrm{C}$ for $30 \mathrm{~s}, 50^{\circ} \mathrm{C}$ for $30 \mathrm{~s}$, and $72^{\circ} \mathrm{C}$ for $30 \mathrm{~s}$. Reactions were then held at $4^{\circ} \mathrm{C}$ until processing. Reaction products were analyzed by electrophoresis through an acrylamide gel $(8.7 \%$ acrylamide $/ 0.3 \%$ bisacrylamide in $1 \times$ Tris-borate EDTA buffer) at $250 \mathrm{~V}$ for $4 \mathrm{~h}$ and were then visualized by illumination of the ethidium bromide stained gel with UV light. A sizing ladder was constructed from the PCR products of strains containing 3 to 14 copies of the repeat, as verified by sequencing. The repeat number of each strain tested was determined by comparison to this sizing ladder.

DNA sequencing. Amplification products from some AJ75/AJ76 PCR reactions were purified with the PCR Preps Kit (Promega Corp., Madison, WI) and se- 
quenced at the MSU/Department of Energy (DOE)-Plant Research Laboratory Sequencing Facility (East Lansing). Primers used for sequencing include AJ75, AJ76, 29RPT-F, 29RPT-R, and AJ218 (5'ATCCTCAGGGCAGCATCA-3').

\section{RESULTS AND DISCUSSION}

PCR primers AJ75 and AJ76 recognize a region of pEA29 internal to that recognized by the primers reported by Bereswill et al. (1) and amplify a band of $844 \mathrm{bp}$ from strain CA11. The sequence of this region of pEA29 from E. amylovora strain CA11 was previously deposited in GenBank (accession \#U19254). Analysis of the sequence revealed 11 identical tandem copies of an 8-bp sequence within the PCR fragment. This repetitive sequence lies within predicted 307-bp Sau3A and 395-bp MspI fragments which are likely to correspond to the variable length restriction fragments reported by Lecomte et al. (5).

PCR products from $E$. amylovora strains CA11, Ea110, and EL01, generated using primers AJ75 and AJ76, were digested with Sau3A. The resulting restriction fragment patterns were identical except that the size of the expected 307-bp band varied between the strains (data not shown). To test the hypothesis that a repeat number polymorphism was responsible for the observed variation, the sequences of the PCR products were obtained. Alignment of the sequences revealed sequence identity between all three strains except for a variation in the number of copies of the 8-bp repeat. A general structure of GATTACA(GAATTACA) ${ }_{n}$ GAATTATCA was found for the repeat region with $n=11,7$, or 6 , respectively, for the three strains.

We next determined the extent of variation in 89 streptomycin-sensitive and -resistant strains of E. amylovora collected from various locations throughout Michigan. To facilitate the differentiation of PCR products which differ in size by as little as 8 bp, new primers (29RPTF/29RPT-R) were developed which flank the repeat region, producing a fragment of $164 \mathrm{bp}$ plus the length of the repeats. All strains, except two, yielded a single 188- to 276-bp fragment which could be assigned to 1 of 12 distinct size classes. The frequency distribution of the size classes found in the collection of Michigan strains is shown in Figure 1. Sequencing of representatives of each of the 12 size classes showed that $n$ varied from 3 to 14 (Fig. 2, marker lanes). Strains from Illinois, Oregon, Washington, and New Zealand were tested and also showed variability ( $n$ $=3,3,6$, and 6 , respectively).

The discriminating power of the gel system that we used in this study allowed us to identify 12 groups rather than the 3 groups reported by Lecomte et al. (5). Our results indicated that this trait had the level of polymorphism needed to characterize the relatively homogeneous population of
E. amylovora found in Michigan apple orchards (9). However, a couple of observations led us to believe that repeat number may not be a stable character of pEA29.
First, two Michigan strains yielded two PCR fragments each instead of just one. Second, when some strains were retested, there was an indication that the number of

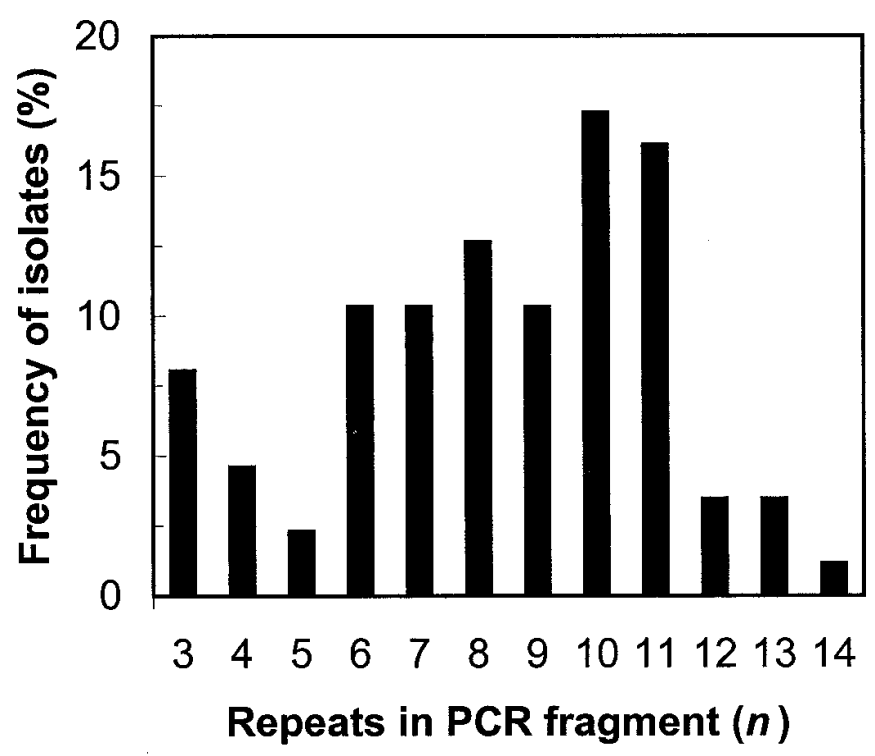

Fig. 1. Frequency distribution in the number of 8-bp repeats found in a fragment of plasmid pEA29 amplified from each of 87 Erwinia amylovora strains from Michigan apple orchards.

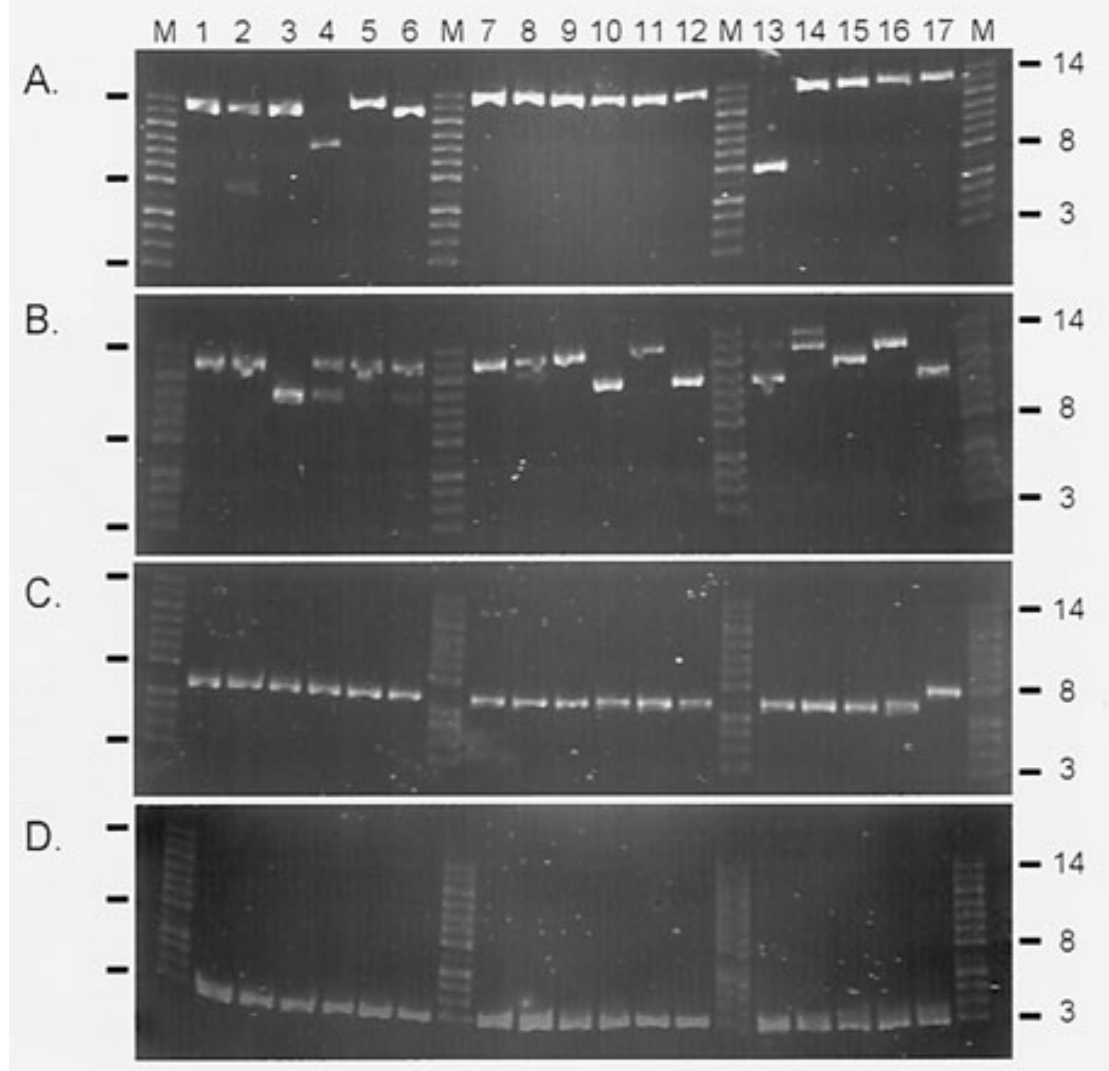

Fig. 2. Stability of the plasmid pEA29 repeat polymorphism during culturing of Erwinia amylovora strains. (A) Strain AM19 with 14 copies; (B) strain BB924b with 13 copies; (C) strain Ea110 with 7 copies; and (D) strain HOR17 with 3 copies of an 8-bp repeat. All strains were cultured overnight in liquid media, streaked onto solid media, and 17 resulting colonies (lanes 1 to 17) were tested for repeat number following polymerase chain reaction (PCR) using primers 29RPT-F and 29RPT-R. Markers (M) are a sizing ladder with bands representing from 3 to 14 copies (189 to $277 \mathrm{bp}$ ) as determined by sequencing the PCR fragments generated from the strains included in the ladder (IL5, HR16, DWW6, EL01, Ea110, D71-1, RN5, CA11b, C3-3, HO63, BB924b, and AM19 with 3 to 14 copies, respectively). 
repeats had changed. For example, a variant of strain CA11 turned up that contained 10 repeats rather than the 11 identified when it was initially sequenced by McManus and Jones (8) and when it was sequenced again at the beginning of this study.

To determine if the rate of change of the repeat number is high enough to effect reliable monitoring of strains over several years, representative strains were retested after passage in liquid culture. Single colonies of four strains with $n=3,7,13$, and 14 were grown overnight in liquid culture; aliquots were then streaked out onto plates and 17 of the resulting colonies from each strain were tested for repeat number (Fig. 2 ). Each of the colonies from the $n=3$ strain displayed a 188-bp band, indicating that all had three repeats. However, many of the colonies (respectively, 1, 10, and 4 out of 17 colonies) from the other three strains displayed different size bands or multiple bands, indicating a change in their repeat copy number after a limited number of generations. Interestingly, strains which contained higher numbers of the repeat appeared to produce altered colonies at a higher rate than strains which contained fewer copies. Data was obtained for two additional strains with $n=11$ and $n=3$ (data not shown); many of the retested colonies from the $n=11$ strain had altered copy number, but none of the colonies from the $n=3$ strain had changed.

Bereswill et al. (1) concluded, based on unpublished data, that restriction fragment length polymorphism in pEA29 was rare. Our results support the conclusion of Le- comte et al. (5) that length variation in at least part of the plasmid is common. We show that the underlying basis for the fragment length variation is the presence of a variable repeat region. Unfortunately, this fragment length polymorphism was found to be unstable, presumably due to homologous recombination between repeats within the plasmid or between two copies of the plasmid (11), and although the rate of change in repeat number in planta has not been established, this marker is presumably not useful for tracking the regional movement of E. amylovora. However, Pst $\mathrm{I}$ restriction digest data (4) showed size variation in at least 8 of the 9 Pst I fragments obtained when pEA29 plasmids purified from several E. amylovora strains were examined. It would therefore be interesting to assess if any of the other polymorphisms could be reliably utilized for differentiating subgroups within those strains of E. amylovora that commonly infect apple and pear.

\section{LITERATURE CITED}

1. Bereswill, S., Pahl, A., Bellemann, P., Zeller, W., and Geider, K. 1992. Sensitive and species-specific detection of Erwinia amylovora by polymerase chain reaction analysis. Appl. Environ. Microbiol. 58(11):3522-3526.

2. Chiou, C.-S., and Jones, A. L. 1991. The analysis of plasmid-mediated streptomycin resistance in Erwinia amylovora. Phytopathology 81:710-714.

3. Dye, D. W. 1968. A taxonomic study of the Genus Erwinia. I The amylovora group. N. Z. J. Sci. 11:590-607.

4. Laurent, J., Barny, M., Kotoujansky, A., Dufriche, P., and Vanneste, J. L. 1989. Characterization of a ubiquitous plasmid in Erwinia amylovora. Mol. Plant-Microbe Interact.
2:160-164.

5. Lecomte, P., Manceau, C., Paulin, J., and Keck, M. 1997. Identification by PCR analysis on plasmid pEA29 of isolates of Erwinia amylovora responsible of an outbreak in Central Europe. Eur. J. Plant Pathol. 103:9198.

6. Manulis, S., Kleitman, F., Dror, O., David, I., and Zutra, D. 1998. Characterization of the Erwinia amylovora population in Israel. Phytoparasitica. 26:39-46.

7. McManus, P. S., and Jones, A. L. 1994. Epidemiology and genetic analysis of streptomycin-resistant Erwinia amylovora from Michigan and evaluation of oxytetracycline for control. Phytopathology 84:627-633.

8. McManus, P. S., and Jones, A. L. 1995. Detection of Erwinia amylovora by nested PCR and PCR-dot-blot and reverse-blot hybridizations. Phytopathology 85:618-623.

9. McManus, P. S., and Jones, A. L. 1995. Genetic fingerprinting of Erwinia amylovora strains isolated from tree-fruit crops and Rubus spp. Phytopathology 85:15471553.

10. Momol, M. T., Momol, E. A., Lamboy, W. F., Norelli, J. L., Beer, S. V., and Aldwinckle, H. S. 1997. Characterization of Erwinia amylovora strains using random amplified polymorphic DNA fragments (RAPDs). J. Appl. Microbiol. 82:389-398.

11. Petes, T. D., and Hill, C. W. 1988. Recombination between repeated genes in microorganisms. Annu. Rev. Genet. 22:147-68.

12. Ritchie, D. F., and Klos, E. J. 1997. Isolation of Erwinia amylovora bacteriophage from aerial parts of apple trees. Phytopathology 67:101-104.

13. van der Zwet, T., and Wells, J. M. 1993. Application of fatty acid class analyses for the detection and identification of Erwinia amylovora. Acta Hortic. 389:233.

14. Zhang, Y., and Geider, K. 1997. Differentiation of Erwinia amylovora strains by pulsedfield gel electrophoresis. Appl. Environ. Microbiol. 63:4421-4426. 